\title{
Equilibrium Solubility Determination and Modeling of Thifensulfuron Methyl in Four Solvents Mixtures
}

Chunjuan Huang*, Haixia Zhang, Renjie Xu

Guangling College, Yangzhou University, Yangzhou, Jiangsu 225000, People’s Republic of China

Corresponding author. Phone: + 86514 87993918; Fax: + 8651487994009 .

E-mail address: HCJtzk1978@163.com 


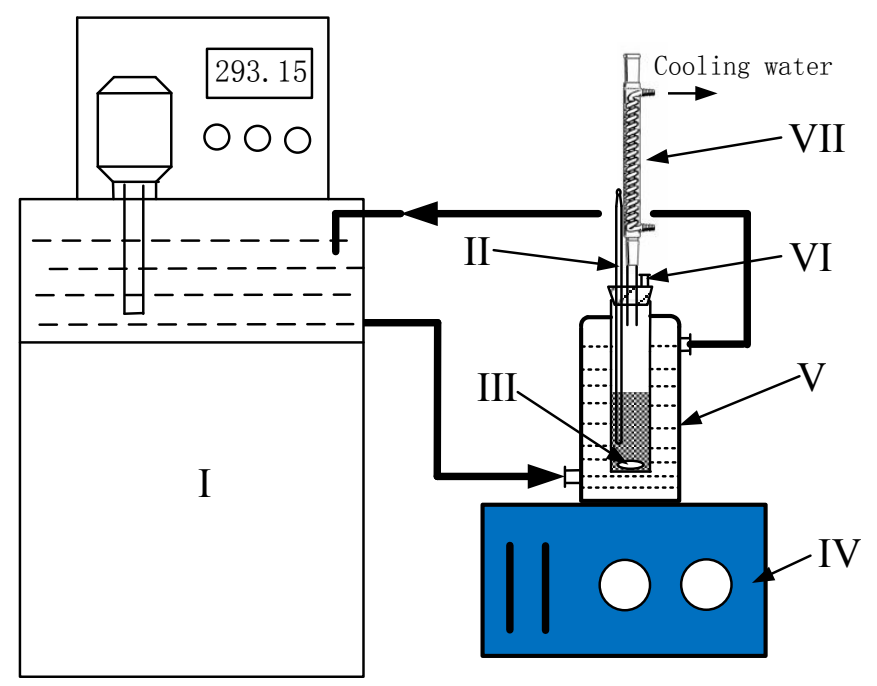

Fig. S1. Schematic diagram of experimental apparatus: I, smart thermostatic water bath; II, mercury-in-glass thermometer; III, magnetic stirrer; IV, stirrer controller; V, jacketed glass vessel; VI, sampling port; VII, condenser. 


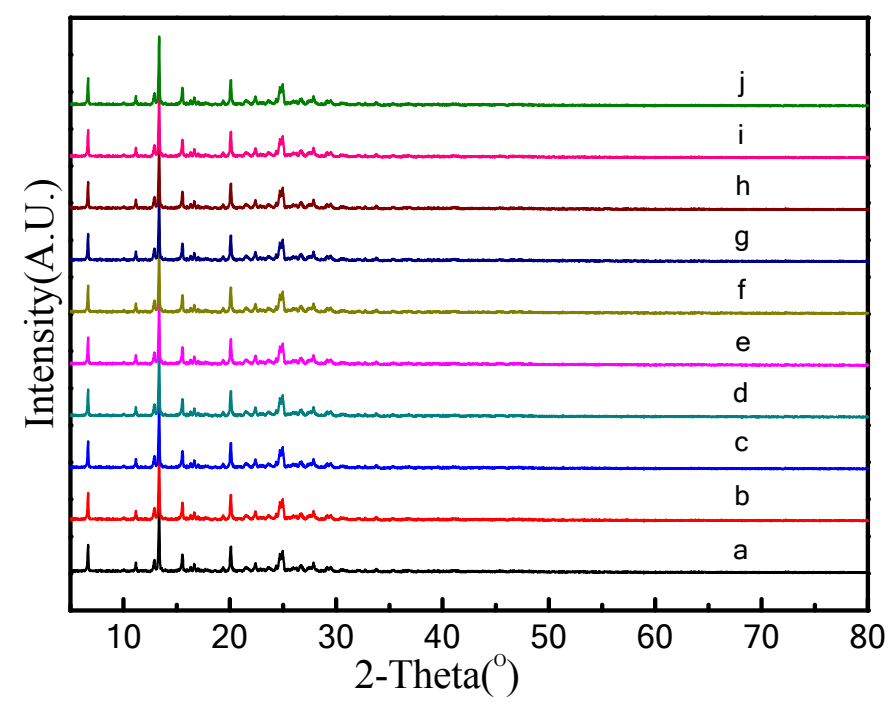

Fig. S2. XPRD patterns of thifensulfuron methyl: (a) raw material; (b) crystallized in methanol; (c) crystallized in ethanol; (d) crystallized in n-propanol; (e) crystallized in DMF; (f) crystallized in water; (g) crystallized in methanol + water mixture; (h) crystallized in ethanol + water mixture; (i) crystallized in n-propanol + water mixture; (j) crystallized in DMF + water mixture. 